\title{
Study of Dynamic Poster Design
}

\author{
Ping Liu \\ School of Art and Design \\ Guilin University of Electronic Technology (GUET) \\ Guilin, China
}

\begin{abstract}
Poster is a graphic design form and visual communication tool derived from advertising and it is firstly associated with commercial activities and have natural links with advertisements. With the social progress, the rapid development of Internet technology and computer technology in the era of Web2.0, its universality, freedom, interactivity and multi-media of digital technology bring infinite possibilities to the field of designing. Vise versa, the internet also develop by virtue of dynamic poster's efficient and rapid propagation characteristics, as the propaganda methods of dynamic posters become more personalized and diversified. This paper briefly describes the development history and design features of dynamic poster.
\end{abstract}

Keywords—dynamic poster; visual art; dynamic

\section{INTRODUCTION}

The poster, originated in Shanghai, China when in the old days as it was used for publicity of events like a drama, a show, a film, ball games etc. It is a method to convey propaganda information to people by using visual communication elements such as pictures, words and colors. Then, it evolves into a kind of advertisement and turn into a common form with its concise language and attractive forms.

\section{ANALYSIS OF THE DYNAMIC POSTERS}

\section{A. Transitions of Poster Forms}

The earliest posters in the world came from an Egyptian notice of a missing person. In the Song Dynasty, Ancient China, the "Definitely choose the brand "White Rabbit"" , a poster of Jinan Kongfu Needle Shop was the earliest one appeared in China. Posters evolved from early handwritten copying into printed ones and became one of the most important media to disseminate information to the public.

After the Industrial Revolution, the development of poster design was influenced by art schools in different periods, such as Dadaism, Cubism, Futurism, and Surrealism. New poster design styles and forms have been created in both visual and ideological aspects.

With the birth of the Bauhaus School of Design in 1919, the role of the milestone in the modern design has been played and European modern design over half a century has been summarized, hence the exploration of the modern poster design and test has been accomplished.
Since the 1980s, poster design has been challenged by new technologies and new media as well as other design fields. This drastic change has stimulated the development of posters.

Designers contribute continuous bold attempt, using visual graphic design (parablepsia), the application of composite material and multiple forms of sensory experience and interaction between the viewer, bringing poster design full of new form of dynamic experience which carries abundant information communication and profound ideology. With the emergence of the computer, the application of network, the intervention of new media, the poster forms become more influential, presenting the diversification, such as interactive poster, $3 \mathrm{D}$ poster, and dynamic poster and so on.

The three-dimensional dynamic image, multimedia art and digital film and TV provide good reference for dynamic poster presentation approaches. Static visual design far from enough to satisfy the aesthetic needs of people in the new century, however, the rapid development of electronic business and the spread of cultural concept can be realized a three-dimensional variable visual via the high-tech means.

The traditional poster design presented the audience two dimensional planes. The digital age is the challenging the viewer's multiple senses. The poster design also starts from the previous plane static state to the dynamic one. The new media carried by the scientific and technological achievements can realize the infinite space of creativity in the design field. Today, people's aesthetic experience break through the former in the past, accepting the new visual media as the aesthetic vision of the public has been expanded. In the new digital era, a brand-new digital technology works as the carrier, which supported by the high-tech, internet. Introduced in computer technology, graphics, images, text, audio, etc. together with emerging media, content of the poster is innovative in introduced the dynamic images such as sound, light, electricity, etc.. This is the namely dynamic posters, unavoidable occurrence in the digital era.

\section{B. The Rise of Dynamic Posters}

First, the function of the poster is mainly to convey personalized information, which is conducive to competition and promotion of sales. As one of the most important communication tools, it is closely related to advertising. 
The poster can convey the exact product information, which can increase the sales and economic growth, and beneficial for the virtuous circle of social production and circulation.

Posters, at the same time, have a certain educative function of new knowledge and new technology, disseminating new inventions and new creation to the public, spreading new knowledge of science, developing the public's vision, resulting in active ideas, and spiritual civilization and enrich cultural life.

With the rapid development of the digital era, the traditional static posters carries comparatively less complicated and limited information, even if it is an ongoing creative design or 3D poster design or other art forms, which all share the characteristic of "space limitation" ,that is, taking insufficient account of the effect of the space. In contrast to static posters, dynamic posters are video posters new media-oriented enjoying features of low cost and rapid propagation and more easily accepted by the audience. Today's fast-paced lifestyle has led to people shortening and even neglect of all kinds of static posters. And dynamic posters is "swinging" due to its strong dynamic art form, image lifelike, vivid, full of fun, and with these characteristics, more likely to attract the attention of the public to the quick, effective and accurate information.

Second, with the widespread use of internet, computers, holographic images, tablet computers, digital products and smart phones, social media is rising up. In particular, the modern network interactive platform, empower every single person the ability to create and disseminate, which is its greatest feature. Anytime and anywhere, people can receive a lot of information through social media, based on the human aesthetic habits and characteristics. The ubiquitous dynamic art forms include cartoon animation, film and television, games, entertainment products. There are boundaries between dynamic art and the traditional static one. What a huge contrast between "dynamic" and "static" ,the former one is quite match the fast pace of modern life, shallow reading habits, fingers sliding screen quickly to get information, as it is how daily life is nowadays.

"In a world of exceptional design information, you can find as much as you want, but you can only choose what is suitable to your personality." The rise of dynamic posters, on the other hand also brings designers infinite challenge. Designers flourished, unfettered by traditional static posters, put into endless design ideas, creativity into the dynamic form, which have unexpected advertising effect of dynamic information transmission. This will undoubtedly help designers to discover and examine the relevance and new combination of things from a new perspective. Thus their creativity is developed and thought is expanded to obtain more creative results.

\section{Theoretical Research on the Characteristics of Dynamic Poster Design}

1) Dynamic propagation: The images of traditional static posters are static and most of them rely on the process of viewer's "gazing at" the pictures, where finds more details to understand the design intention of the work. Static posters convey information through the generalized theme of the picture, hoping that the viewer can understand the purpose of the designer. Dynamic posters, on the contrast, attract viewers' attention by continuous movement in the works, and also break the shackles of the static expression form on the time axis. The more appropriately dynamic and static combines with the detailed idea processed, the viewer aftertaste can be achieved more vividly.

Poster displaying form is shifting from the traditional static kind to dynamic inevitably due to the development in the digital age. Designers can create coherent images, collect sound and high-tech real simulation to present the dynamic way of information spreading, cater for the public aesthetic value and entertainment combination, which dynamic poster basic attributes.

Through intensively dissemination in network, dynamic poster is the final result of extension and evolution from static poster. The information age, based on the changing forms of new media, has greatly enriched and expanded the mode of communication that already formed in human society, bringing great changes to the integration of visual communication design. Its integration with the advantages of advertising media such as newspapers, radio, TV, makes it possible to combine propagating symbols ---the words, pictures, business, with high-tech means, the manifestation is of diversified.

2) Diversified forms: In hand-painted traditional dynamic posters, many of the basic design are depicted by the computer software, frame by frame, then relevant text information, image color are added, edited and plate-making to the end.

3D dynamic poster increases visual appeal by using 3Dmax/Maya and other design software to model the material, edit the dynamic trajectory, thus, its dynamic effect is prominent.

Dynamic web pages posters, is a dynamic form of posters of communication and the Internet, using FLASH design software, taking vector mainly as design elements, exported in GIF format, easy communication, and its file storage is small.

Motion picture poster is mainly used in film poster publicity. In the era of film craze and popularity, film propaganda also considers dynamic elements as a means of promotion to increase the viewer's visual pull, thereby the box office rises.

Mobile phone posters take smart phone as one of the carriers of dynamic posters because smart phone has much wider space in interactivity, and mobile APP can present different dynamic posters to cater to current mobile reading habits. After all, nowadays people's addiction on mobile phones is far more than one had imagined.

3) Strong compatibility: Compatibility is so strong that almost all browsers now support formats of dynamic poster 
file. When the web page is opened, it can be displayed directly, and the interface of digital products can be displayed smoothly without download of cumbersome tools or difficult software. A questionnaire survey on a large number of internet users shows that 95 percent of people would prefer dynamic posters directly instead of graphic posters or auto-playing posters. The current animated GIF images and expressions, even small video screens, are being watched by users who are especially in lower age group favorably. From the perspective of user experience, more and more young users are more likely to show up in different media without hindrance. At the same time, there are fewer and fewer clicks needed in the browsing process.

4) Low cost: HTML5 has been wound down and overused, thus, traditional static graphic poster have to give way to dynamic poster which is the new king. It can satisfy the tastes of users to attract audiences impressively with unparalleled performance on content, rich tension, dynamic forms. It not only reinforce the memory of the audience for the poster, but also has low production cost compared with traditional advertising which cost a huge amount of advertising dollars, dozens of times more, in $\mathrm{TV}$, radio or magazines.

However dynamic posters can appear in social network, such as the computer terminals, mobile client, mobile phone APP. The design expenditure is a one-time pay, but can pass to over hundred million internet users by clicks to achieve propaganda purposes. Compared to traditional media, it greatly reduces the cost of advertising.

5) Small files but fast propagation: GIF files are most widely adopted in dynamic posters, with a huge advantage, its file size. Files size determines the speed of transmission. Among the current favorites of social media, Weibo, WeChat, etc., all support GIF's display, which enable the dynamic poster spread immediately. Mobile phone is a digital product of people always in hand. A computer screen has been transferred to mobile phone where more and more people are used to read all kinds of information and high client ratio appear in users sharing sites. Having been read or viewed once, the excellent dynamic poster information will soon shared by users. Dynamic posters are also popular in the internet because of their small and tiny file formats, incomparable compatibility.

\section{CONCLUSION}

The development of dynamic poster is the product of modern digital visual communication. There is no space limitation and it can convey message well. With the help of multimedia means, it highlights the theme in rich form and attracts more viewers' interest; show more professional designed graphics, music and dynamic demonstration. The comprehensive effects bring the audience a new audio-visual experience, provides an ideal channel to people who believe "efficiency first" and leaves field more open to the contemporary designers.

\section{REFERENCES}

[1] Meng Juan. Research on Design and Display of Digital Dynamic Poster, [D],Xi'an University of Technology,2008.

[2] SunYan,QiaoJie.. Analysis of Dynamic Posters in Internet Era[J]. Popular Literature and Art,2016( 10 ):43. 